\title{
Optimization of Process Parameters of Plasma Arc Cutting Using Taguchi's Robust Design Methodology
}

\author{
Dr.S.V.S.S.Srinivasa Raju ${ }^{1}$, K.Kodanda Ram ${ }^{2}$ D.V.S.S. Satyanarayana ${ }^{3}$, \\ M.Sai Nishood Goud ${ }^{4}$ \\ ${ }^{I}$ (Professor, Dept. of Mechanical Engineering, VNRVJIET, India) \\ ${ }^{2}$ (Associate Professor, Dept. of Automobile Engineering, VNRVJIET, India) \\ ${ }^{3}$ (Associate Professor, Dept. of Mechanical Engineering, CMR TECHNICAL CAMPUS, India) \\ ${ }^{4}$ (Dept. of Mechanical Engineering, VNRVJIET, India)
}

\begin{abstract}
One of the most important nonconventional machining methods is Plasma Arc Machining. Its high accuracy, high finishing, ability of machining any hard materials and to produce intricate shapes increased its demand in the market. It is cheaper than Laser cutting and about ten times faster than Oxy-fuel Cutting and hence is a better option for cutting many jobs. In this work the process parameters that influence the quality of cut in terms of the bevel angle have been analyzed statistically for cutting Mild Steel E350 grade sheets. The Current, Cutting Speed and Arc Gap have been considered as the important parameters. Taguchi Design of Experiments was used and analysis was done by Minitab 17 software. After performing Analysis of Means $(A N O M)$, the optimum parameters have been found, percentage contributions of the parameters on the Bevel Angle have been obtained using Analysis of Variance (ANOVA), Regression equation being computed for the bevel angle and surface plot has been generated to understand the interactions of two factors on the Bevel Angle. From ANOVA it has been observed that the cutting speed influences the Bevel Angle the most with contribution of $62.18 \%$ followed by arc gap with $15.16 \%$ and the current $12.08 \%$.
\end{abstract}

Keywords: Mild Steel E350 material, Orthogonal Array, Plasma Cutting, Surface Plot and Taguchi Method.

\section{Introduction}

Plasma arc cutting (PAC) is a non-conventional manufacturing process capable of processing a variety of electrically conducting materials. It is characterized by an electric arc established between an electrode and the work piece. The electrode acts as the cathode, and the work piece material acts as the anode. PAC process is to increase the energy density generated by the system. In order to achieve higher cutting thickness without losing the quality of the cut, many parameters must be taken into consideration. PAC process shown in Fig.1.

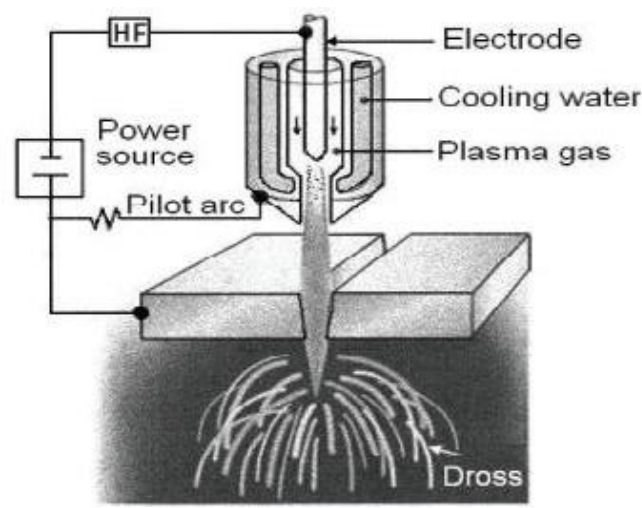

Fig.1 Plasma arc cutting principle

The purpose of this study is to understand the influence of Plasma Arc Cutting on E350 Mild Steel material of bevel angle as quality characteristic and to select Orthogonal Array using design of experiments. This work also involves selection of parameters minimizing the quality characteristic using Taguchi design of experiments. It also calculates percentage contribution of the independent variables on bevel angle using regression equation. A study has been conducted by analyzing the interaction of parameters affecting the bevel angle using surface plots. This work contributes to the development of Plasma Arc Cutting process to achieve desired quality at an optimum cost. 


\section{Objectives}

a) To study about the influence of Plasma Arc Cutting parameters on Mild Steel.

b) To design a series of experiments using Design of Experiments (DOE) layout in order to study about Plasma Arc Cutting (PAC).

c) To study surface plots in order to analyze the interactions between two parameters for affecting the Bevel Angle.

d) To study about the best combination of solution for minimizing the Bevel Angle with Taguchi Method.

e) To understand the percentage contribution of the considered process parameters on the Bevel Angle and compute a Regression equation for the Bevel Angle.

\section{Experimental setup}

Experiments were performed on a CNC plasma cutting system (MESSER Germany Kjellbert) with a dual flow torch. The cuts were performed on $6.5 \mathrm{~mm}$ thickness E350 mild steel sheets, with the use of oxygen as plasma (primary) gas and air as shielding (secondary)gas. The specimens were made up of a linear cut $150 \mathrm{~mm}$ in length and a rectangular cut of $50 \mathrm{~mm}$ side, in order for the cutting edge roughness, the conicity and the heat affected zone (HAZ) to be measured. The materials were allowed to cool to room temperature between cuts. Every experiment was conducted two times, measurements were taken along the cut in the straight line portion. Each measurement was taken approximately in the middle of the work piece's thickness and the average value of measurements was used and treated as the result of a single experiment.

Table: 1 Mechanical Properties of Mild Steel

\begin{tabular}{|c|c|c|}
\hline \multicolumn{3}{|c|}{ MECHANICAL PROPERTIES OF MILD STEEL - E350 GRADE } \\
\hline Yield Strength(MPA) & Tensile Strength (MPA) & Elongation \% \\
\hline 240 & 450 & 25 \\
\hline
\end{tabular}

Table: 2 Plasma Machine Control Factors and Levels

\begin{tabular}{|c|c|c|c|}
\hline Factors/ Levels & Cutting Current (A) & Cutting Speed (mm/min) & Cutting Height (mm) \\
\hline 1 & 60 & 1800 & 3 \\
\hline 2 & 90 & 2500 & 4 \\
\hline 3 & 130 & 2800 & 5 \\
\hline
\end{tabular}

\section{Results and Discussion for Mild Steel - E350 Grade}

The response factor measured is the Bevel Angle which is the major quality characteristic in Plasma Arc Cutting. The measurements are made on the straight line portion of the considered profile using a Vernier Bevel Protractor. Two trials were performed on the same side of the part at the center of the straight line portion with accuracy up to 5 minutes angle. The values are tabulated after converting the angles to degrees completely considering 60 minutes $=1$ degree.

The SN ratios and Means being evaluated using the Minitab 17 software.

Table: 3 Plasma Arc Cutting Results

\begin{tabular}{|c|c|c|c|c|c|c|c|}
\hline S.No. & $\begin{array}{c}\text { Cutting } \\
\text { Current (A) }\end{array}$ & $\begin{array}{c}\text { Cutting Speed } \\
(\mathbf{m m} / \mathbf{m i n})\end{array}$ & $\begin{array}{c}\text { Cutting } \\
\text { Height }(\mathbf{m m})\end{array}$ & Trial-1 & Trial-2 & S/N ratio & Means \\
\hline 1 & 60 & 1800 & 3 & 1.16 & 1.33 & 10.6702 & 1.245 \\
\hline 2 & 60 & 2500 & 4 & 12.5 & 12.66 & -21.9338 & 12.580 \\
\hline 3 & 60 & 2800 & 5 & 11.25 & 11.33 & -21.0539 & 11.290 \\
\hline 4 & 90 & 1800 & 4 & 5 & 5.18 & -14.1357 & 5.090 \\
\hline 5 & 90 & 2500 & 5 & 3.5 & 3.66 & -11.0798 & 3.580 \\
\hline 6 & 90 & 2800 & 3 & 14.66 & 14.83 & -23.3730 & 14.745 \\
\hline 7 & 130 & 1800 & 5 & 3.33 & 3.66 & -10.8786 & 3.495 \\
\hline 8 & 130 & 2500 & 3 & 17.16 & 17.33 & -24.7334 & 17.245 \\
\hline 9 & 130 & 2800 & 4 & 16.16 & 16.33 & -24.2145 & 16.245 \\
\hline
\end{tabular}

From among 9 experiments Optimum values of Plasma Cutting Current 90, Cutting Speed of 1800mm/min and Cutting Height of $5 \mathrm{~mm}$.

\subsection{Analysis of Means}

The analysis has been performed by the Minitab 17 software. The analysis performed were Analysis of Mean (ANOM) for obtaining the optimum parameters.Analysis of Variance(ANOVA) for obtaining the 
percentage contributions of each parameter on the bevel angle,the regression equation for the bevel angle being estimated and the surface plot for the interaction of two most contributing parameters have been plotted.

Table: 4 Response table for means

\begin{tabular}{|c|c|c|c|c|}
\hline S.No & Level & Current(A) & $\begin{array}{c}\text { Cutting } \\
\text { Speed(mm/min) }\end{array}$ & $\begin{array}{c}\text { Arc Gap (or) Arc } \\
\text { Height (mm) }\end{array}$ \\
\hline 1 & 1 & 8.053 & 2.958 & 10.760 \\
\hline 2 & 2 & 7.805 & 11.135 & 11.305 \\
\hline 3 & 3 & 12.328 & 14.093 & 6.122 \\
\hline 4 & Delta & 4.523 & 11.135 & 5.183 \\
\hline 5 & Rank & 3 & 1 & 2 \\
\hline
\end{tabular}

From the above table it can be noted that as per the rankings given the speed influences the Bevel Angle the most followed by the Arc Gap and then the Current.

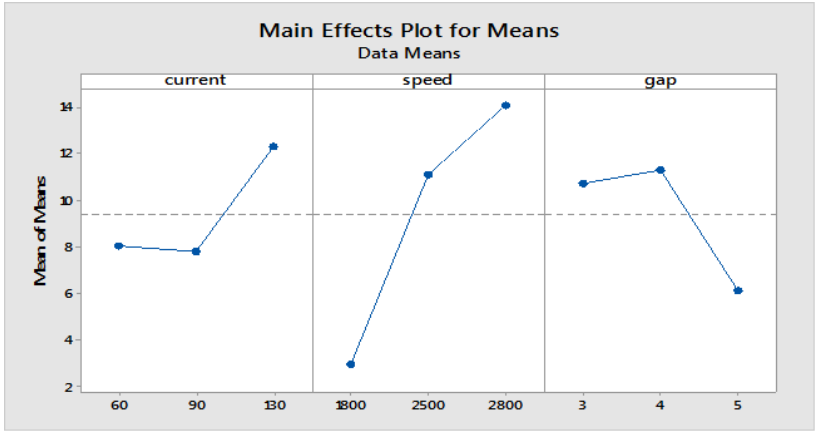

Fig.2 Main effects plot for Means of Bevel Angel

From the above graph of mean of Bevel Angle and various factors, it can be observe that Bevel Angle is least at a current setting of 90Amps,Cutting Speed of $1800 \mathrm{~mm} / \mathrm{min}$ and an Arc Gap (Arc Height) of $5 \mathrm{~mm}$.

\subsection{Optimum Parameters}

From the Mean of Means for Bevel Angle graph the optimum parameters have been noted and tabulated as follows:

Table: 5 Optimum Parameters

\begin{tabular}{|c|l|l|}
\hline S.No & Parameter & Value \\
\hline 1 & Current & $90 \mathrm{~A}$ \\
\hline 2 & Cutting Speed & $1800 \mathrm{~mm} / \mathrm{min}$ \\
\hline 3 & Arc Gap & $5 \mathrm{~mm}$ \\
\hline
\end{tabular}

\subsection{Analysis of Variance}

Table: 6 Analysis of Variance (ANOVA)

\begin{tabular}{|c|l|c|c|c|c|c|}
\hline S.No. & \multicolumn{1}{|c|}{ Source } & DF & Adj SS & Adj MS & F-Value & P-Value \\
\hline $\mathbf{1}$ & Cutting Current & 2 & 77.596 & 38.798 & 6.28 & 0.015 \\
\hline $\mathbf{2}$ & Cutting Speed & 2 & 399.196 & 199.598 & 32.33 & 0.000 \\
\hline $\mathbf{3}$ & Cutting Height & 2 & 97.356 & 48.678 & 7.88 & 0.008 \\
\hline $\mathbf{4}$ & Error & 11 & 67.920 & 6.175 & & \\
\hline $\mathbf{5}$ & Total & 17 & 642.068 & & & \\
\hline
\end{tabular}

From the above ANOVA table the percentage contributions can be calculated as the ratio of Adj SS values of that particular parameter to the total value. $\mathrm{P}$ value less than 0.05 indicate model terms are significant.

\subsection{Percentage Contribution}

From the Analysis of Variance (ANOVA) table the percentage contributions are calculated by dividing the Adj SS values of that particular parameter with the total Adj SS value.

Table: 7 Percentage Contribution

\begin{tabular}{|c|l|l|}
\hline S.No. & Parameter & Contribution \\
\hline 1 & Cutting Current & $12.08 \%$ \\
\hline 2 & Cutting Speed & $62.18 \%$ \\
\hline 3 & Cutting Height & $15.16 \%$ \\
\hline
\end{tabular}




\section{Regression Equation}

By performing Regression Analysis for the above data using Minitab Software, the below equation has been obtained for the Bevel Angle in terms of the various parameters.

$$
\text { Bevel Angle }=-13.87+0.0639 \text { current }+0.01123 \text { speed }-2.319 \text { gap }
$$

From the above equation, the value of bevel angle can be predicted at the optimum parametric conditions with Current $=90$ Amps, Cutting Speed $=1800 \mathrm{~mm} / \mathrm{min}$ and Arc Gap $=5 \mathrm{~mm}$

Hence Bevel Angle $=-13.87+0.0639 \times(90)+0.01123 \times(1800)-2.319 \times(5)$

$$
\mathrm{BA}=0.5 \text { degrees }
$$

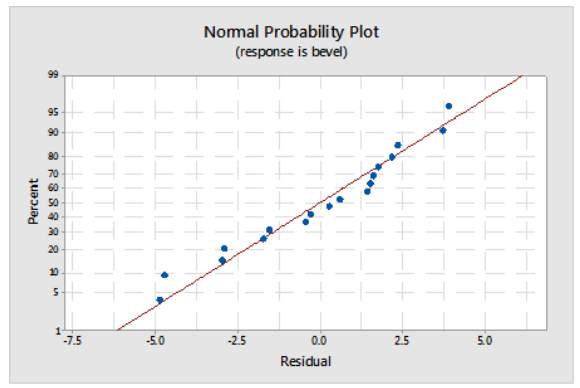

Fig.3 Normal Probability Plot for Residuals of Bevel Angle

The above graph indicates that the residual follows a straight line and there are no unusual patterns or outliers. As a result, the assumptions regarding the residuals were not violated and the residuals are normally distributed.

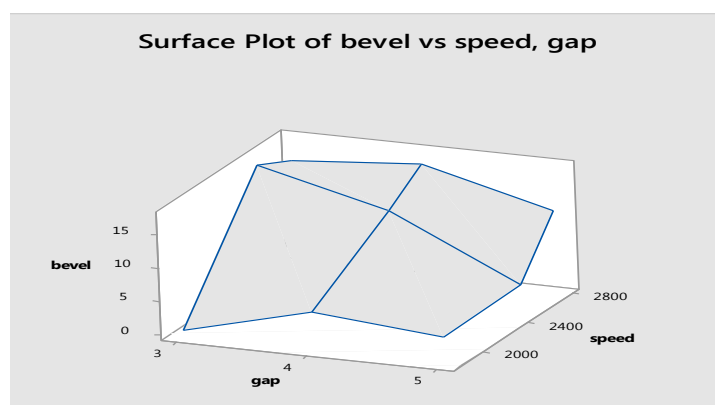

Fig.4 Surface Plot of Bevel vs Cutting Speed, Arc Gap

The above graph indicates that the effect of the interaction between Arc Gap and Cutting Speed on the bevel angle and it can be observed that smaller Arc Gap with low Cutting Speed gives a smaller Bevel Angle. At a given Arc Gap, as the cutting speed increases the Bevel Angle also increases.

\section{Confirmation test}

Table: 8 Confirmation test results

\begin{tabular}{|l|c|c|c|}
\hline Response Factor & Trial-1 & Trial-2 & Average Value \\
\hline Bevel Angle & 40 & $45^{\prime}$ & $42.5^{\prime}$ \\
\hline
\end{tabular}

From the confirmation test, the average bevel angle has been obtained as 42.5 ' i.e.0.7 degrees.

\section{Conclusion}

This project has presented an application Taguchi method to the optimization of the machining parameters of Plasma Arc Cutting Machine. As shown in this study, the Taguchi method provides a systematic and efficient methodology for determining optimal parameters with far less work than would be required for most optimization techniques.

The experiments have been conducted for Mild Steel material E350 Grade of $6.5 \mathrm{~mm}$ thickness which is utilized for various applications. The combinations for the experiments have been obtained by the Design of 
Experiments (DOE). The PAC parameters studied were the Current, Cutting Speed and the Arc Gap using L9 Orthogonal Array.

From Analysis of Means (ANOM) the optimum parameter values have been tabulated. These values act as an anchor for further analysis considering even more experiments (27) so that the parameters can be refined for the best outcome.

The Analysis of Variance (ANOVA) has been conducted to find the percentage contributions of each parameter on the Bevel Angle and it has been found that the Cutting Speed contributes $62.18 \%$, Arc Gap contributes $15.16 \%$ and the Current contributes $12.08 \%$ with an acceptable error of $10.58 \%$.

The Regression Equation has been computed and a surface plot has been generated for the interaction between Cutting Speed and Arc Gap to analyze their combined effect on the Bevel Angle. From this plot it has been observed that for a smaller arc gap with a low Cutting Speed the Bevel Angle is small.

\section{References}

[1]. Amit Sharma, Optimization of Kerf Quality Using Robust Design of Experiments During Nd: YAG Laser Cutting of Thin Aluminum Alloy Sheet for Straight Profile, MIT International Journal of Mechanical Engineering, Vol. 1, No. 1, 2011, 1-8(8) ISSN No. 2230 - 7699.

[2]. R. Bhuvenesh, M. H. Norizaman and M. S. Abdul Manan, Surface Roughness and MRR Effect on Manual Plasma Arc Cutting Machining, International Scholarly and Scientific Research \& Innovation, Vol. 6, 2012.

[3]. Joseph C. Chen and Ye Li, Taguchi Based Six Sigma Approach to Optimize Plasma Arc Cutting Process: an Industrial Case Study, International Journal of Advanced Manufacturing Technology, 41, 760-769(10). 